\title{
New cultivar of mountain ash (Sorbus) Siberian breeding
}

\author{
Sergey Asbaganov ${ }^{1 *}$, Anna Lokteva ${ }^{1}$ and Zhanna Rupasova ${ }^{2}$ \\ ${ }^{1}$ Central Siberian Botanical Garden SB RAS, 630090, Novosibirsk, Zolotodolinskaya st., 101, Russia \\ ${ }^{2}$ Central Botanical Garden of the National Academy of Sciences of Belarus, 220012, Minsk, \\ Surganova st., 2c, Republic of Belarus
}

\begin{abstract}
The northern regions of Russia are characterized by a relatively poor composition of the cultural dendroflora, that due to harsh climatic conditions. To create resistant varieties, it is necessary to attract local highly winter-resistant forms and on their basis to obtain hybrids with foreign species with outstanding characteristics of economically useful traits. As a result of hybridization of the breeding form of S. sibirica with a undersized and large-fruited breeding form of $S$. sambucifolia was obtained the heterosic hybrid 'Sharik' $\left(\mathrm{F}_{1} S\right.$. sambucifolia $\times$ S. sibirica $)$ that combining valuable decorative and nutritional qualities, with ultra-fast of fruiting start and highly winter-resistant.
\end{abstract}

\section{Introduction}

Among food wild plants of Western Siberia, Siberian mountain ash (Sorbus sibirica Hedl.) is one of the most promising for the introduction and selection of fruit crops. This situation is primarily due to the unique biochemical composition of its fruits, which have high nutritional and medicinal value. The main disadvantage that restrains the widespread use of this plant in culture is the bitter taste of the fruit. The only variety cultivated in the Novosibirsk region with dessert flavor is Sorbus aucuparia 'Nevezhinskaya'. This variety has a number of significant disadvantages: tall, pyramidal crown, late entry into fruiting, reduced winter hardiness.

To create sustainable decorative and food varieties in Siberia, it is necessary to hybridize best forms of $S$. sibirica with foreign species, characterized by a complex of economically valuable traits: winter hardiness, large-fruited, stunted, lack of bitterness in fruits. Among the great species diversity of mountain ash, two of the most promising sources combining the above listed complex of characters in their genotypes are Sorbus sambucifolia (Cham. et Schlecht.). M. Roem and intergeneric hybrid $\times$ Sorbocotoneaster pozdnjakovii Pojark. [1, 2].

\section{Material and methods}

\footnotetext{
*Corresponding author: cryonus@mail.ru
} 
The work was carried out in the Central Siberian Botanical Garden of the SB RAS (CSBG SB RAS) on the basis of the bioresource scientific collection "Collections of living plants in open and closed ground", UNU No. USU 44053.

The work used standard methods for studying fruit crops [3].

A comprehensive assessment of the biochemical composition of the fruit was carried out at the CBG NAS of Belarus in accordance with generally accepted methods $[4,5]$. In fresh averaged samples of ripe fruits, the content was determined: dry solids - according to GOST 28561-90 [6]; ascorbic acid - by the indophenol method [5]; titratable acids volumetric method [8]. The total content of soluble sugars - accelerated semi-micromethod [10]; the amount of pectin substances - calcium pectate method [8]; anthocyanin pigments - according to the method of T. Swain, W.E. Hillis [9]; actually anthocyanins, the sum of catechins (using a vanillin reagent) [10] and the sum of flavonols (in terms of rutin) - by the photocolorimetric method [5]; tannins - by the Leventhal titrimetric method [11].

\section{Results and discussion}

According to our data, one of the most promising ways to improve selected forms of $S$. sibirica is their interspecific hybridization with hardy selected forms of $S$. sambucifolia and some forms of $S$. aucuparia. Already in the first generation, from these combinations of crosses, it is possible to obtain fully winter-hardy hybrid genotypes in Siberia, which are superior in most economically valuable traits to European mountain ash varieties.

One of these hybrid forms was obtained as a result of hybridization of breeding forms of CVPR-51 and B1 and was registered as a new cultivar 'Sharik' (f. BK-1 $\left[\mathrm{F}_{1}(S\right.$. sambucifolia $\times$ S. sibirica)] (Fig.).

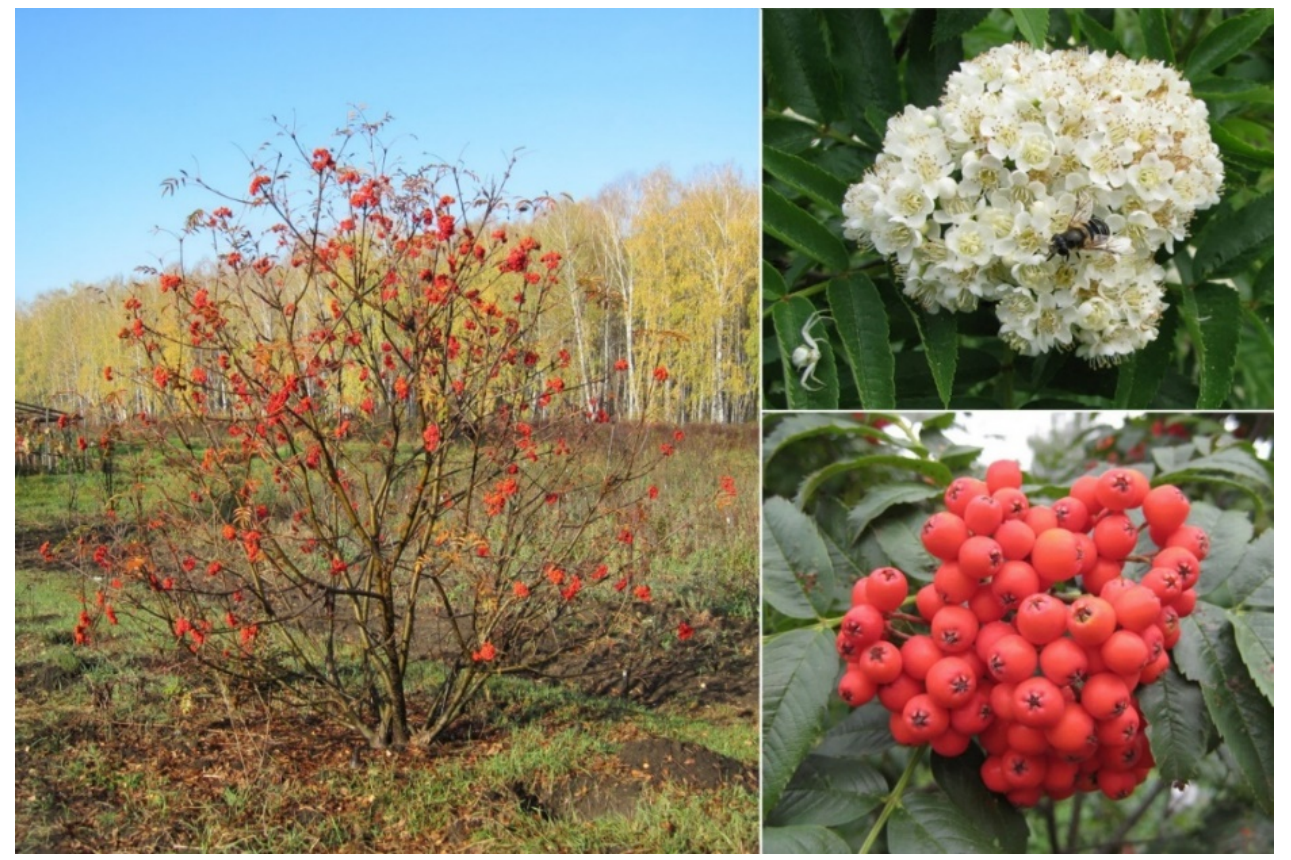

Fig. Interspecific hybrid 'Sharik' (BK-1) in the collection of the CSBG (Novosibirsk)

At the age of 17, it is a bush with a spherical crown with a diameter of about 3.5 meters. The structure of vegetative and generative organs is intermediate between the original 
parent species. Cultivar 'Sharik' begins ultra-fast of fruiting due to the heterosis effect: seedlings with grafted buds bloom in the second year after graft. The average weight of the fruit is $0.9 \mathrm{~g}$, the taste is acidic with bitterness, juicy flesh, vitamin C $258.5 \mathrm{mg} \%$, anthocyanins $1757.6 \mathrm{mg} \%$ bioflavonoids $3515.6 \mathrm{mg} \%$, pectins $4.6 \%$ (table). Under the conditions of Novosibirsk, the Sharik is completely winter-hardy, self-sterile, and forms highly fertile pollen $(88.7 \%)$. With artificial pollination of Siberian mountain ash, fruit setability reaches $80.3 \%$. Similar hybrids of $S$. sambucifolia with $S$. aucuparia (Nevezhinskaya variety) set fruits that are completely devoid of bitterness, but less winterhardy in Siberia.

Cultivar 'Sharik' is registered as a universal variety combining food and decorative qualities. It retains its decorative qualities throughout the growing season due to its spherical crown and shiny leaves. In a leafless state, like most mountain ash, it is decorative due to brightly colored fruits.

Table. The biochemical composition of mountain ash fruits of cultivars `Sharik` and 'Nevezhinskaya'

\begin{tabular}{|c|c|c|}
\hline & 'Sharik' (BK-1) & 'Nevezhinskaya' \\
\hline Dry matter, \% & $26.5 \pm 0.8$ & $25.6 \pm 0.6$ \\
\hline Titratable acidity, $\%$ & $11.4 \pm 0.1$ & $12.7 \pm 0.0$ \\
\hline Ascorbic acid, mg\% & $258.5 \pm 4.6$ & $245.7 \pm 6.0$ \\
\hline Glucose, $\%$ & $3.9 \pm 0.1$ & $3.8 \pm 0.0$ \\
\hline Fructose, $\%$ & $4.7 \pm 0.1$ & $6.4 \pm 0.1$ \\
\hline Sucrose, $\%$ & $0.6 \pm 0.0$ & $0.8 \pm 0.0$ \\
\hline The amount of sugars, $\%$ & $9.2 \pm 0.1$ & $11.0 \pm 0.1$ \\
\hline Fructose / glucose & $1.2 \pm 0.0$ & $1.7 \pm 0.0$ \\
\hline Monosugar / disaccharide & $14.0 \pm 0.3$ & $12.6 \pm 0.6$ \\
\hline Sugar Acid Index & $0.8 \pm 0.0$ & $0.9 \pm 0.0$ \\
\hline Hydropectin, \% & $0.9 \pm 0.0$ & $0.9 \pm 0.0$ \\
\hline Protopectin, $\%$ & $3.7 \pm 0.0$ & $2.8 \pm 0.0$ \\
\hline The amount of pectins, $\%$ & $4.6 \pm 0.0$ & $3.7 \pm 0.1$ \\
\hline Protopectins / Hydropectins, $\%$ & $4.0 \pm 0.1$ & $3.1 \pm 0.1$ \\
\hline Anthocyanins, mg\% & $112.0 \pm 2.0$ & $84.0 \pm 6.0$ \\
\hline Leukanthocyanins, mg\% & $1645.6 \pm 9.6$ & $748.0 \pm 28.3$ \\
\hline The amount of anthocyanin pigments, $\mathrm{mg} \%$ & $1757.6 \pm 10.4$ & $832.0 \pm 22.7$ \\
\hline Catechins, mg\% & $507.0 \pm 4.5$ & $265.2 \pm 9.0$ \\
\hline Flavonols, mg\% & $1251.0 \pm 8.6$ & $1362.1 \pm 3.6$ \\
\hline Flavonols / Catechins & $2.5 \pm 0.0$ & $5.1 \pm 0.2$ \\
\hline The amount of bioflavonoids, $\mathrm{mg} \%$ & $3515.6 \pm 9.7$ & $2459.3 \pm 11.3$ \\
\hline Phenol Carboxylic Acids, mg\% & $1410.0 \pm 15.3$ & $493.3 \pm 20.3$ \\
\hline Tannins, \% & $4.0 \pm 0.0$ & $2.2 \pm 0.0$ \\
\hline
\end{tabular}

\section{Conclusion}

According to most economic indicators, except for the total sugar content, the 'Sharik' hybrid cultivar is not inferior to the Nevezhinskaya variety; it is completely stable in the 
Siberian climate. It can be used in home gardening as an ornamental and food plant in single and group plantings.

This work was supported by the state project number: AAAA-A17-117012610054-6 for the Central Siberian Botanical Garden (CSBG) SB RAS). Materials of the bioresource scientific collection of the CSBG SB RAS "Collections of living plants in open and closed ground", USU No. 440534 were used.

\section{References}

1. A.B. Gorbunov, V.S. Simagin, Yu.V. Fotev, Introduction of non-traditional fruit, berry and vegetable plants in Western Siberia (Geo, Novosibirsk, 2013)

2. S.V. Asbaganov, E.V. Kobozeva, A.V. Agafonov. Interspecific and intergeneric hybridization in solving systematics and introduction of mountain ash, in Proceeding of the International. Scientific conference Actual issues of conservation of biological diversity. Introduction of plants (Ridder, 2015)

3. E.N. Sedov, P.P. Ogoltsova, Program and Methods of Variety Studies of Fruit, Berry and Walnut Fruits (VNIISPK, Orel, 1999)

4. Zh.A. Rupasova, Biochemical composition of fruits of rare horticultural crops in Belarus (Belarusian science, Minsk, 2014)

5. A.I. Ermakov, Methods of biochemical research of plants (Agropromizdat, Leningrad, 1987)

6. GOST 28561-90 fruit and vegetable processing Products. Methods for determining dry substances and moisture (standards Publishing house, Moscow, 1991)

7. B.P. Pleshkov, Workshop on plant biochemistry (Kolos, Moscow, 1985))

8. A.T. Markh, T.F. Zykina, V.N. Golubev, Technochemical control of canning production (Agropromizdat, Moscow, 1989)

9. T. Swain, W. Hillis, J. Sci. Food Agric. 10, 1 (1959)

10. V.Yu. Andreeva et al., Pharmacy, 3 (2013)

11. Determination of the content of tannins in medicinal plant raw materials, State Pharmacopoeia of the USSR (Medicine, Moscow, 1987) 